\title{
Registration and Licensure of Nutrition Professionals in Florida ${ }^{1}$
}

\section{Linda B. Bobroff ${ }^{2}$}

It is critical for consumers to be aware of who is qualified to practice nutrition or dietetics. Dietetics is a specialized field of study that allows persons completing their studies to take a national registration examination to become a registered dietitian (RD). $\mathrm{RD}$ is a well-recognized term, protected from use by unqualified practitioners. However, self-styled nutritionists or nutrition counselors often provide advice and counseling to those willing to pay for it. Unqualified practitioners can place their clients at risk for adverse health effects, and the public deserves to be protected from them.

Registration and licensure of nutrition professionals exist to protect the public from people who are not qualified to practice as nutrition professionals, just as licensure of physicians protects the public from people who are not qualified to practice medicine.

The following is information about dietetic registration (a national credential), and licensure (a state-specific credential). Forty-six states have their own form of licensure or credentialing for nutrition professionals. In Florida, there are three credentials that allow people to legally practice as a nutrition or dietetics professional: Registered Dietitian (RD), Licensed Dietitian/Nutritionist (LD/N), and Licensed Nutrition Counselor (LNC). Specific areas of practice, such as private consulting, public health, and long-term care, have different requirements.

\section{Registered Dietitian (RD)}

RDs study a required program of course-work, earn at least a bachelors degree, and complete 900 supervised practice hours of preprofessional experience in order to qualify to take the RD exam. Once they pass the exam and earn their RD status, registered dietitians are required to earn at least seventy-five hours of continuing education units (CEUs) every five years, ensuring their continued expertise in nutrition. CEUs must be approved by the Commission on Dietetic Registration (CDR).

Continuing education moves dietetics professionals beyond the entry-level knowledge and skills needed to pass the national registration exam. It ensures that professionals engage in a program of lifelong learning to remain competent in their field of practice. Because nutrition is an ever-changing field, this CEU requirement is critical.

1. This document is FCS 8765, one of a series of the Department of Family, Youth and Community Sciences, Florida Cooperative Extension Service, Institute of Food and Agricultural Sciences, University of Florida. Publication date: July 2004. Please visit the EDIS Web site at http://edis.ifas.ufl.edu

2. Linda B. Bobroff, PhD, RD, LD/N, professor, Department of Family, Youth and Community Sciences, Cooperative Extension Service, Institute of Food and Agricultural Sciences, University of Florida, Gainesville, FL 32611. Reviewed by Laura K. Guyer, PhD, RD, Suwannee River AHEC; Christine A. Stapell, MS, RD, LD/N, Florida Dietetic Association; and Glenda L. Warren, MS, RD, University of Florida. 
The CDR is the authoritative body for dietetics registration (for more information about CDR, see their website: http://www.cdrnet.org/).

The CDR's certification programs are accredited by the National Commission for Certifying Agencies (http://www.noca.org/ncca/ncca.htm), which is the accrediting arm of the National Organization for Competency Assurance (http://www.noca.org).

\section{Licensed Dietitian/Nutritionist (LD/N)}

Licensing laws are statutes that explicitly define scopes of practice for professions. These laws protect the public by ensuring that only persons who are qualified in a particular field are allowed to practice in that field. Where such a law exists, it is illegal to perform as a professional in that field without first obtaining the appropriate license from the state.

Florida enacted its licensure law for the practice of nutrition and dietetics in 1988. According to Florida's licensure law: "No person may engage for remuneration in dietetics and nutrition practice or hold himself out as a practitioner of dietetics and nutrition practice unless a person is licensed in accordance with the provisions of ss.

4689.501-468.518."

A licensed dietitian/nutritionist in Florida should use the designation LD/N. They may use the words dietitian, licensed dietitian, nutritionist, or licensed nutritionist, in connection with their name or place of business to indicate that they are licensed in the state of Florida.

LD/Ns must meet academic and preprofessional practice criteria similar to those for RDs in order to take the state licensure examination. In addition, licensed practitioners in Florida need to complete an ongoing program of continuing education to maintain their licenses. This is critical to ensure that the public will receive up-to-date and accurate information when they seek the services of an LD/N.

According to CDR: "Dietetics practitioners are licensed by states to ensure that only qualified, trained professionals provide nutrition services or advice to individuals requiring or seeking nutrition care or information. Only state-licensed dietetics professionals can provide nutrition counseling. Non-licensed practitioners may be subject to prosecution for practicing without a license."

Information about licensure in Florida may be obtained from:

The Florida Department of Health

Dietetics and Nutrition Practice Council

52 Bald Cypress Way, BIN \#C05

Tallahassee, FL 32399-3255

Tel: (805) 245-4373

Website: http://www.doh.state.fl.us

\section{Licensed Nutrition Counselor (LNC)}

When the licensure law was enacted in Florida, individuals who had been practicing nutrition counseling prior to 1988 were allowed to apply for the designation licensed nutrition counselor (LNC). To indicate that they are licensed in the state of Florida, LNCs may use the words nutrition counselor, licensed nutrition counselor, nutritionist, or licensed nutritionist in connection with their names or places of business.

Because, prior to 1988 , there was no law that regulated the practice of nutrition counseling, LNCs may have been highly qualified or completely unqualified in the area of nutrition/nutrition counseling. Individuals who choose to seek out the services of an LNC will need to inquire about his or her educational background and training in order to determine whether or not the person is qualified to practice. Whatever their background, LNCs must earn continuing education units to maintain their license to practice in Florida. Over the years, many have chosen not to maintain their licenses, and those persons are no longer allowed by law to practice nutrition counseling in the state.

Additional information about licensure in Florida, and the Dietetics and Nutrition Practice Council, may be obtained from the Florida Department of Health website, http://www.doh.state.fl.us/mqa/dietetics/ndhome.html 